\title{
Investigating Women's Experiences of Asthma Care in Pregnancy: A Qualitative Study
}

\author{
Chervonne Chamberlain ${ }^{1}$, Graham R. Williamson ${ }^{*}, 2$, Beatrice Knight ${ }^{1}$, Mark Daly ${ }^{1}$ and \\ David M.G. Halpin ${ }^{1}$
}

\author{
${ }^{1}$ Royal Devon and Exeter Hospital NHS Foundation Trust, Barrack Rd, Exeter, EX25DW, UK \\ ${ }^{2}$ School of Nursing and Midwifery, Plymouth University, Plymouth, PL48AA, UK
}

\begin{abstract}
Background: Most asthmatic women have normal pregnancies and complications are infrequent when their asthma is well-controlled. Symptom control and medical treatment are concerning to pregnant asthma suffers, as is the impact that their illness and treatment might have on their unborn baby. The aim was to investigate in a qualitative study the thoughts and feelings of women's experiences of asthma in pregnancy. Twenty-two women with asthma who had a pregnancy within two years were asked to participate. Seven women were interviewed when data saturation was achieved. Interviews were transcribed and analysed using the 'Framework' Method, independently analysed by two researchers and consensus reached concerning the construction of themes.
\end{abstract}

The key themes that emerged were Asthma and pregnancy; Pregnancy and post-natal experiences; and Health professionals.

These findings are globally interesting because of the prevalence of maternal asthma and they illustrate participants' experiences concerning their asthma care and their views on its improvement. Pregnant asthmatic women have concerns about their care and treatment which might be alleviated by outreach, joint working between respiratory doctors and nurse specialists, midwives and General Practice nurses. Targeted educational activities could form a part of this care delivery.

Keywords: Asthma, interviews. midwife, nurse, pregnancy, qualitative research.

\section{INTRODUCTION}

Most women with asthma have normal pregnancies and the risk of complications is low when their asthma is wellcontrolled [1, 2]. For about a third of women, asthma symptoms will worsen and for about a third it will improve during pregnancy, but it is highly unlikely that women will develop acute asthma during labour; those with uncontrolled asthma are more likely to have maternal and foetal complications including hypertension, pre-eclampsia, vaginal haemorrhage, complicated labour, foetal growth restriction, pre-term birth, and increased perinatal mortality [2]. It is safer for mother and baby if pregnant women with asthma are treated and have their symptoms controlled by medication than if they remain untreated and have frequent exacerbations [1,2]. It may also be the case that babies born to mothers with uncontrolled asthma and increased severity of attacks are at greater risk of asthma themselves [3] although this evidence is disputed [4].

Achieving asthma control is even more important given that the risk of adverse effects from medications used to control asthma is low for the baby. This is true for inhaled medicines including beta- 2 agonists and corticosteroids, as

*Address correspondence to this author at the School of Nursing and Midwifery, Plymouth University, Plymouth, PL48AA, UK;

Tel: 01752587476; E-mail: gwilliamson@plymouth.ac.uk well as oral corticosteroids and theophylline; steroid tablets early in pregnancy are generally considered safe, but while the majority of studies show no increased risk, a couple suggest they may be associated with a slightly increased risk of cleft lip $[1,2,5]$. It also seems that maternal treatment with oral steroids while breastfeeding does not cause problems for the infant [2]. Overall, optimal control of asthma is the aim during pregnancy; this requires appropriate education on management and self-management [6], and a careful discussion of the risks and benefits for individual patients concerning treatment options and their potential side-effects [7]. Despite reassurance concerning the safety and efficacy of these common asthma treatments contained in the United States National Asthma Education and Prevention Program (NAEPP) and the United Kingdom British Thoracic Society/Scottish Intercollegiate Guidelines Network (BTS/SIGN) [1, 2], issues of illness, symptom control and medical treatment are of some concern for pregnant asthma suffers, as is the impact that their illness and treatment might have on their unborn baby. This has led to reports of women unilaterally discontinuing or reducing their treatment without consultation or discussion with their healthcare professionals $[8,9]$, reflecting a perceived lack of support and guidance [8]. Indeed, it appears that women overestimate the risk of birth defects to the foetus from oral steroids, perceive some risk from inhaled medications, and that this is worse when they use inhaled corticosteroids regularly and are of a more anxious general disposition [10]; 
it may also be the case that family practitioners are unsure how best to manage asthma in pregnancy for their patients [11].

Although asthma and pregnancy management guidelines $[1,2]$ are widely available, they may not be used as effectively as they could be, with one study indicating that whilst most family physicians considered guidelines useful, $64 \%$ admitted that they followed them seldom or never [12]. When educational activities specifically address issues of asthma and pregnancy, significant differences can be made in women's adherence to treatment plans, leading to decreased usage of reliever medications and night symptoms through to improved self-management [13]. An international study also indicated that women want better education and support to help them deal with their concerns [14].

Despite a wealth of research on asthma and pregnancy, there are few qualitative studies illustrating how recently delivered asthmatic mothers felt about their care, support and medication during their pregnancy, and it is in this context that this study sought to hear the voices of women and uncover their perspectives in a qualitative study. The study aim was to investigate in a qualitative study the thoughts and feelings of women's experiences of asthma in pregnancy.

\section{MATERIALS AND METHODOLOGY}

There are a small numbers of studies exploring the issues of asthma and pregnancy from the point of view of women themselves, meaning that a qualitative study was justified to explore the issues that concerned the participants themselves. A generic qualitative approach to data collection and analysis was used rather than following prescriptively the tenets of one philosophical qualitative perspective, because a deeply theoretical design was not logistically feasible or necessary to explore the research aims [15]. Generic or narrative qualitative approaches have become increasingly popular in healthcare research and are suited to investigations stemming from clinical practice [16, 17]; this study design allowed the perspectives of asthma care by recently pregnant women to emerge.

Caelli et al. [15] argue that generic qualitative research is not a theoretical, but is particularly well-suited to clinical settings where researchers have well-developed clinical questions which are frequently derived from their own personal experience. Thus whilst generic qualitative research still conforms to a constructivist imperative, Caelli et al. [15] go some way in recasting the concern with methodological congruence that has been a feature of nursing research to that of broad agreement with epistemological congruence in qualitative research. They further argue that it is important that methods are appropriate for qualitative researchers, as it is the 'fit' between methods and epistemology that is one aspect of the assessment of rigour. Cooper and Endacott [17] argue that certain features of qualitative research are important in establishing rigour, and these are an audit trail, in which researchers keep accurate and detailed records and describe the research process; saturation, whereby the researcher continues to recruit participants until no new data emerge, saying five to eight participants are usually sufficient for a homogenous sample; inter rater reliability, in which interview transcripts can be reviewed independently, aiming at consensus about their construction of interpretations and themes. Caelli et al. [15] further add the need for reflexivity in rigorous research reports, and that in order to ensure credibility, generic qualitative researchers must discuss their theoretical positioning, show the congruence between methodology and methods; the strategies used to establish rigor; and the analytic lens through which the data are examined. These issues of rigour and credibility will be analysed in relation to the conduct of this study in the discussion section.

Semi-structured individual interviews were used to collect data as these are best used for research that focuses on the knowledge, beliefs and attitudes of participants and are particularly useful in generic qualitative research as they allow flexibility during the interview if a participant introduces a topic earlier than anticipated, or digresses into interesting areas that the researcher had not anticipated, or where clarification is required [16]. There is the added advantage in semi-structured individual interviewing of minimising any potential disclosure of sensitive issues between participants that might have been an issue on a focus group situation, whilst at the same time allowing us to collect the in-depth data that were required to understand the issues more fully.

\section{Ethical Issues}

Ethical approval was obtained from the local NHS National Research Ethics Service (NRES) Committee and sponsorship and governance approval were provided by the NHS foundation trust in which the study took place. Women gave written informed consent and were guaranteed ethical protection by ensuring that they were free to withdraw their data at any time, non-participation would have no impact on their care, their data were made anonymous, held securely, and that they understood the purpose of the study and its implications. Women were offered the option of being interviewed at home or at the hospital site. All appointments were made at the women's convenience and the interviewer is female (CC).

\section{Participants and Sampling}

Participants were recruited from the records of the NHS foundation trust hospital respiratory department, and contact was then made by the lead researcher (CC) by letter and phone calls to arrange suitable times for the interviews. Sampling was purposive in order to access those women with the experiences necessary to investigate the research aims.

Eligibility criteria were:

- Confirmed diagnosis of asthma.

- $\quad$ Recent pregnancy up to 2 years previously.

- Current, ex and non-smokers.

- Willing and able to provide informed consent.

Exclusion criteria were:

- Unable to give informed consent. 
Table 1. Semi-structured interview schedule.

\begin{tabular}{|c|c|c|}
\hline General Area & Examples & Might Lead to \\
\hline Perceptions about having Asthma & $\begin{array}{l}\text { Time since diagnosis? } \\
\text { Perceptions of severity? } \\
\text { Otherwise healthy? }\end{array}$ & $\begin{array}{l}\text { How they perceived the diagnosis } \\
\text { Activities they might avoid } \\
\text { Self image? }\end{array}$ \\
\hline $\begin{array}{c}\text { Management activities and } \\
\text { attitudes }\end{array}$ & $\begin{array}{c}\text { Clinic attendance? } \\
\text { Health professionals seen? } \\
\text { Medication use? } \\
\text { Special advice? } \\
\text { Advice from elsewhere, e.g. family, friends? }\end{array}$ & $\begin{array}{c}\text { Value of regular monitoring } \\
\text { Medications in general and alternatives? } \\
\text { Compliance } \\
\text { Surrounding / informal knowledge }\end{array}$ \\
\hline $\begin{array}{l}\text { Pregnancy as an additional } \\
\text { condition }\end{array}$ & $\begin{array}{l}1^{\text {st }} \text { pregnancy?/ previous problems } \\
\text { Any change in asthma (either way) } \\
\text { Any particular concerns }\end{array}$ & $\begin{array}{c}\text { Expectations } \\
\text { Own monitoring process } \\
\text { Directly addresses information gaps }\end{array}$ \\
\hline Delivery experience & $\begin{array}{c}\text { Where did you deliver? } \\
\text { Mode of delivery? } \\
\text { Post natal experience? } \\
\text { Support given during and after birth }\end{array}$ & $\begin{array}{l}\text { Impact of significant experience, } \\
\text { Perceived impact of asthma on delivery experience. } \\
\text { Provision of info and practical support during intra and post-partum. }\end{array}$ \\
\hline Aspects of child rearing & $\begin{array}{l}\text { General plans } \\
\text { Breast feeding } \\
\text { Infant asthma }\end{array}$ & $\begin{array}{c}\text { Previous advice } \\
\text { Information gaps } \\
\text { Contact with health professionals? }\end{array}$ \\
\hline
\end{tabular}

\section{Procedure}

Twenty-two women with asthma who had had a pregnancy within the last two years were invited to participate. Seven women were interviewed when data saturation was achieved. Data collection took place between March 2012 and September 2012. The interviews lasted approximately one hour, but were not artificially truncated or prolonged past the point at which an interviewee was ready to finish. The interviews were semi-structured using a schedule of areas to be addressed (see Table 1) but focused on the concerns of the interviewee to guide the order and length of discussions and the introduction of additional topics. With the women's permission the interviews were tape-recorded, and the recordings transcribed verbatim except that names and identifying features were omitted to preserve anonymity.

\section{Data Analysis}

The transcribed digital recordings were analysed using the recognised qualitative approach from the 'Framework' Method [18]. This process was designed in order to make the development of coherent concepts more manageabe from the mass of data in the form of text which results from qualitative data collection. Ritchie et al. [18] outline the following steps: Familiarisation and construction of initial themes or concepts. Here, the researcher takes a general overview of the data and starts to build a preliminary picture of the themes that might evolve, noting commonalities between data. It is useful although not essential that the researcher conducts all the interviews, as a general level of familiarisation will already be evident. In this study, CC conducted and transcribed all the interviews her self, so was very familiar with the data, and she further immersed herself in the data by listening to recordings before completing the analysis.

The next step is indexing, labelling and tagging the data, and here the researcher constructs links between categories by sorting them according to levels of generality and employing a hierarchical structure so that themes and subthemes start to emerge. Notes were applied by CC to this study's data and themes were manually grouped and collected on paper, so that a chart or pictorial structure was created that could be shared, discussed and agreed between $\mathrm{CC}$ and $\mathrm{GW}$, so that these relatively raw data were sorted by theme or concept. This latter step summarises or synthesises the data, reducing its volume as well as identifying its essence. In this stage, $\mathrm{CC}$ and $\mathrm{GW}$ maintained the participants' voices by illustrating the emerging themes with verbatim quotes. As a last process, data were subject to descriptive analysis, where the themes are refined and finalised. $\mathrm{CC}$ and $\mathrm{GW}$ met at the end of the analytical process described above, reassessed and re-evaluated the themes based on their separate analyses of the data, and as a result the final thematic analysis was developed and agreed.

\section{RESULTS}

\section{Characteristics of the Sample}

Of the seven who took part, two were first time mothers, five had a family history of asthma, and two had previous hay fever. For four mothers, their asthma worsened during pregnancy whilst for three, their asthma improved. Three interviews took place in the respiratory clinic and four at home. The interviewee's baby was present in six of the interviews. 
Table 2. Themes and sub-themes.

\begin{tabular}{|c|c|}
\hline Theme & Sub-theme \\
\hline Asthma and pregnancy & $\begin{array}{c}\text { Self-management including fears; } \\
\text { lack of recognition of symptoms; } \\
\text { poor knowledge of inhaled therapy; } \\
\text { risk factors; } \\
\text { anxieties including drugs, procedures, risks versus benefits; } \\
\text { general understanding of asthma; } \\
\text { concealing symptoms. }\end{array}$ \\
\hline Pregnancy and post-natal experiences & $\begin{array}{c}\text { Impact of exacerbations on baby; } \\
\text { changes to asthma; } \\
\text { post-natal experience; } \\
\text { breastfeeding benefits. }\end{array}$ \\
\hline Health professionals & $\begin{array}{l}\text { Lack of regular contact; } \\
\text { midwife support; } \\
\text { interaction with healthcare professionals; } \\
\text { education. }\end{array}$ \\
\hline
\end{tabular}

\section{Themes and Sub-Themes}

Table 2 indicates the themes and sub-themes that emerged from data analysis. The themes were Asthma and pregnancy; Pregnancy and post-natal experiences; and Health professionals.

\section{Asthma and Pregnancy}

Those women whose asthma worsened reported fears and difficulties associated with self-management in the community, creating serious anxiety states for them when they could not breathe during exacerbations. For example:

I just couldn't get air in and ended up with having a few panic attacks as well, because I couldn't... It was frightening I suppose, that's why. APO7.

I actually thought I was dying. It was horrible. APO6.

So that makes you panic. Which then obviously brings on...more anxiety. And then you can't breathe again...I ended up in quite a serious situation and I was really frightened. AP01.

This anxiety was worsened when they did not recognise or fully appreciate the meaning or severity of their symptoms:

I didn't realize it was asthma really, I didn't think about it, I don't know, I just got on with it. I would just go up a hill and start puffing...I really just thought I was unfit or something because I was heavier and pregnant and it was just the weight, I didn't really think about it. APO7.

I didn't really know what was happening you see I thought it would just go away... because I was pregnant and there was nothing you could do and I would just have to see it through. AP05.

It was clear that some of the women did not understand how their medications worked or what they were for:

The brown inhaler just wasn't effective, they tried me with a round purple one... and I had a red and white one...the twisty one, well I couldn't get anything out of that. I don't think I'd got enough suction to get anything out of it. AP06.

This lack of understanding contributed to their anxieties concerning drugs:

Obviously the word steroid makes you think, "Oh my God, big baby". APO1.

I didn't really know if I should be stopping that medication. That was my main concern. And the GP didn't really know and just said stop it. APO2.

I would be very cautious about what I would take but I would look into it a lot before I took anything. APO4.

I think another thing was that after I had [baby's name] I heard something on the news about inhalers being linked to birth defects. Because I already had her it didn't bother me...but I think if I had been pregnant and seeing that I would have been worried. AP05.

The women's anxieties included medical procedures, particularly X-Rays and their impact on the baby, but others decided that the benefits outweighed the risks when baby might be starved of oxygen.

But obviously if you can't breathe and are getting into real trouble then you have to do something, then you'd have to weigh it up but if you can't breathe and you keel over then it's probably not good for your baby, they need 
oxygen... they are not getting any oxygen, then it's stupid not to give in. APO7.

Like the night I came into hospital I had to have a chest X-Ray and I got really worried about that but they said ... well, with you not well the baby could be worse so I had to have it done and I hoped that [baby's name] was alright. APO5.

Some women identified that their husband or partner had no understanding of asthma; coupled with others' lack of understanding this made them conceal their symptoms with potentially serious consequences:

[My husband], he's away with the fairies, he doesn't see anything ... he doesn't really see past those kind of things...he just lets me get on with it. APO4.

[My husband], he'd have just told me to get on with it. APO6.

That day at work everyone was saying I looked terrible and I felt terrible, couldn't walk very well...I just thought I'd got a cold...My husband doesn't do illness well so I just got on with it. AP05.

Because he [the woman's partner] doesn't have it he doesn't understand. He doesn't realize how bad it can be and how scary it can be he doesn't think about it. AP07.

It is quite frustrating because I don't want the children to see me like it either so I tend to try and hide it away from them if I'm having a bad day. APO4.

\section{Pregnancy and Post-Natal Experiences}

The women were very concerned about what impact their exacerbations might have on the baby after it was born. For those whose asthma had improved during pregnancy, this respite was considerable and enjoyed:

[My asthma] stopped completely, it was like a miracle cure. I think I used my blue inhaler twice throughout my whole pregnancy. I stopped using the brown one and never had any symptoms at all. AP04.

I felt the healthiest I'd ever felt with my asthma... I went throughout my pregnancy, all the time I was breast feeding for $13 \frac{1}{2}$ months without a cold, cough and I didn't require any antibiotics or any steroids. AP02.

However, postnatally, their asthma returned:

The week I had him it came back straight away...I think personally that its hormones...As soon as I had him it just seemed to come back. AP04.

Then when I stopped breast feeding and started getting periods again and I don't know if this is a coincidence but then my chest started playing me up again. AP02.
Those whose asthma worsened were unprepared for this, and were taken aback by the severity of their new symptoms:

During the pregnancy it got worse very, very quickly and wasn't under control. AP01.

However, for this woman, the asthma improved immediately after delivery.

Afterwards I felt so much better. You know the minute he was born... I had my first dip about a week or two after he was born. But immediately after I was fine. AP01.

When I was younger it was always on exertion that I would get asthma problems ...but it was mild then with my first pregnancy, it became quite moderate, and after the second pregnancy it became quite severe and I ended up in hospital. AP07.

The women clearly identified that there were benefits to their breast feeding, believing it could protect their babies from allergies and asthma.

[Breast feeding] is the best thing for them and I know that if you breast feed there is less chance of them getting things like asthma and eczema and all the nasty allergies and things ... all of my nieces and nephews were bottle fed and all of them have got quite a lot of different minor health problems... whereas [my children] have not got any. APO4.

Obviously knowing that breast is best for your baby...I know that it is so good and I am hoping that it will prevent allergies for [baby's name] in the future and maybe asthma as well. AP02.

\section{Health Professionals}

These women did not generally have regular contact with community practitioners, either GPs or practice nurses, who may have had an understanding of their asthma. Whilst such staff were accessible if necessary, there seemed to be no management plans in place to monitor pregnant women with asthma.

No I never saw my doctor ... I think I saw my GP once actually when I was pregnant. I think I was due to see the GP the day I came into hospital instead. AP05.

I saw her once [the Practice Nurse] when I originally was diagnosed and I didn't see her again because I was pregnant and everything seemed to have settled down. And then I went back to see her again when it seemed to come back again. AP04

Whenever I needed to see him [GP] I just rang and he saw me that day... he just said play it by ear really. AP06.

Midwives were described as supportive, but paid more attention to pregnancy issues than asthma: 
They did ask me my medical history but that was it really. They concentrated more on the baby. AP02.

Half the trouble is the midwives don't know... She said to see the GP the next day. AP05.

[Midwives] ask you what they know about. I don't think asthma is particularly one of them...They were really good but they didn't mention asthma. APO7.

It put my mind at ease and then they did a scan or just listen to the heartbeat. [The midwives] came around every day to reassure me. AP01.

I was on two monitors, one for me and one for [baby's name] so I knew he was still OK. AP03.

Some of the women described serious delays in obtaining acute care when their exacerbations of asthma required admission.

He took me to the Medical Assessment Unit and the stupid receptionist up there she put it down as shoulder pain rather than chest pain so I sat up there for about an hour. AP06.

They left me for about two hours out of breath and no one would give me a nebuliser or anything to help me ... The first doctor he saw the X-Ray and said it looked like I had an infection and they were going to treat me for that and then the next one said "you don't appear to have an infection"... and the third one said "I think it's probably asthma" and started me on that route... but they still weren't giving me anything until the day after. AP07.

Once admitted to hospital they appreciated the care given by medical staff and respiratory nurses.

The Consultant was good when he came to see me, he said he thought it was asthma and gave me the Symbicort [a combined preparation of inhaled steroid and bronchodilator] and the blue one and said "do you know much about it?" He said [he would] get the Respiratory Nurse to come and see me and talk to about it. So that was helpful from then onwards. But before that no one really said much, they were trying to work out if it is [asthma] or not. APO7.

The women wanted more education so that they could understand what was happening to them:

If you are an asthmatic before you get pregnant you should be aware of the seriousness of the severity of asthma because I just thought it was just two puffs of an inhaler and it will be all better. AP01.

I think a leaflet would be good. Just a basic leaflet and obviously I do have some knowledge but for people that don't have knowledge, I think just a basic leaflet about asthma in pregnancy and maybe some dos and don'ts. You know, or who to contact if you have any questions. I just think that would be good. AP02.

I think that if I had been warned that things might change, obviously there is nothing I could have done to stop it but I could have been aware and expected it and not panic as it really took me by surprise and I was quite scared. AP01.

If you know you've got something then you know what to do about it. I wouldn't just think "now I will just ignore the symptoms getting worse" I would have a plan...I would try to stop it getting to that terrible state. AP07.

\section{DISCUSSION}

It is clear from this qualitative study that the women who took part have concerns about their asthma and its relationship to their pregnancy, their clinical care, prognosis and treatment that are strikingly similar to international literature on asthma and pregnancy; in particular, they were concerned about the impact that their asthma might have on their baby, and weighed up the risks of medications and procedures before deciding to have them, which is safer than discontinuing treatment $[1,2]$.

It is also clear that despite national and international guidelines [1,2], and recommendations from other research studies [6] personal management plans were not being used and monitoring of pregnant asthmatic women as recommended did not occur. Issues of illness, symptom control and medical treatment concerned this study's pregnant asthma suffers, as did the impact that their illness and treatment might have on their unborn babies, but whilst this study's participants did not speak about unilaterally discontinuing or reducing their treatment without reference to their healthcare professionals as had been the case in other studies $[8,9]$, they did want greater support and guidance and asked for education so that they could better understand what was happening to them. It seems as if primary care staff in this study were unsure how best to manage asthma in pregnancy for their patients, as has been previously reported [11]: this knowledge gap was convincingly reported by this study's participants, and the authors concluded therefore that asthma and pregnancy management guidelines were not used effectively with these women [12]. Due to the fact that this study was carried out at a single site, it is not possible to say whether this is the case nationally and further research to clarify whether this is the case is warranted.

If there is a knowledge gap relating to community practitioners' understanding of asthma and pregnancy, it seems likely therefore that adherence to treatment plans could be improved so that self-management recommendations in the UK might more closely be aligned to the UK BTS/SIGN guidelines [2]. If this was achieved, it has the potential to produce reductions in drug usage and complications [13,14]. Help for pregnant women to understand and manage their asthma is particularly important as it has been shown that women with an increased perception of control over their asthma and reduced anxiety 
have lessened risk of exacerbations, caesarean section, and preterm birth [20], and that active, individualised management strategies and include education and treatment can improve asthma care for women during pregnancy [21]. Improving maternal asthma outcomes during pregnancy is particularly important because it has been shown in a large Danish cohort study [22] that the long term consequences of poorly controlled asthma for the child can be severe and long-lasting: at baby cohort median age 6, asthma was associated with an increased risk of infectious and parasitic diseases, diseases of the nervous system, ear, respiratory system and skin, and other unconfirmed risks of endocrine, metabolic and digestive system diseases and malformations. Whilst one flaw with that study [22] is the use of dichotomous variables 'yes/no' to define symptoms of asthma during pregnancy which omits to measure the severity and number of exacerbations, these potential morbidities are a powerful stimulus for healthcare providers to aim at optimum asthma control for their pregnant asthmatic patients.

Implementing structured management plans has the potential to demonstrate measureable outcomes including degree of asthma control, oral corticosteroid use, asthma exacerbations and hospital admissions, work sickness rates, neonatal adverse events [23] and could provide a uniform approach to advice and support where this is lacking [24]. Indeed, similar to our study, it has been found elsewhere that midwives' current knowledge of asthma in pregnancy was highly variable, with few knowing the potential consequences of poor asthma management, or implementing consistent approaches to antenatal asthma management [25]. It has also be shown in a small doctoral thesis using an experimental design that a multidisciplinary model of care involving education, regular monitoring and follow-up in routine antenatal care can be valuable in improving asthma control [27].

\section{Rigour and Credibility}

It is essential that qualitative research is rigorous and credible $[6,15,17,19]$, and in order to demonstrate this to be the case in this study, we adhered to three of the principles described by Cooper and Endicott [17], namely the need for an audit trail, saturation and inter rater reliability, as well as Caelli et al.'s [15] concepts of method congruence and reflexivity.

Regarding a research audit trial, full notes of recruitment and sampling activities were kept by $\mathrm{CC}$, and notes made from all research team meetings and the decisions that occurred there. Regarding saturation, Cooper and Endicott [17] argue that between five and eight participants is usually a sufficient number for saturation to occur when there is a homogenous sample (as ours was), and indeed saturation was reached when seven women had been interviewed. Regarding inter rater reliability, two researchers (CC \& GW) analysed the transcripts independently and compared analyses, producing consensus about the interpretation of data and the themes that emerged. On the issue of congruence between methods and methodology [15], it is clear that the choice of individual semi-structured interviews with asthmatic mothers was an appropriate data collection choice to gain in depth qualitative data [16] and helped us to understand their issues and concerns about their asthma and pregnancy. As a generic qualitative research study, we sought to inherit no claims to knowledge derived from particular schools or philosophical traditions other than qualitative research itself, and this is justified and acceptable in health-related studies seeking analytic description [25].

Caelli et al. [15] further add the need for reflexivity in rigorous research reports: an element of reflexivity is widely regarded as required to demonstrate rigour [16] and the lead researcher (CC) continuously reflected upon her relationships with participants and how this might influence her analysis and interpretation of data.

Regarding rigour in data analysis, we used the Framework method [18] which is not aligned with a particular epistemological viewpoint or theoretical approach and therefore can be adapted for use in inductive or deductive analysis [26], and so was highly appropriate for our descriptive purposes.

\section{CONCLUSION}

These findings are interesting to others nationally and internationally because of the prevalence of maternal asthma, and illustrate participants' experiences concerning their asthma care and their views on its improvement. This small qualitative study shows that recently-delivered asthmatic mothers identified their asthma care as variable, with some examples of good care but clear areas where care could be improved if international clinical guidelines $[1,2]$ were fully implemented to inform individual patient management plans.

That pregnant asthmatic women have concerns about their care and treatment is understandable: pregnancy is a worrying time on many fronts and asthma increases these anxieties. These anxieties may be alleviated by a better understanding of asthma amongst community personnel who care for pregnant women, as they could then more effectively educate pregnant asthmatic women, and this finding supports previous studies [20, 21, 24].

Better asthma control also has potential beneficial consequences for off-spring in terms of reducing their risk of many childhood diseases [22]. It is possible that improving education could be achieved by joint working between tertiary care Respiratory Nurse Specialists and primary care Midwives, General Practitioners and Practice Nurses, and further research investigate should investigate the potential for practice development in this area. This joint working could fruitfully examine the implementation of national and international guidelines $[1,2]$ and the construction of a care pathway for asthma in pregnancy [24], which could improve asthma control [27].

\section{AUTHORS' CONTRIBUTIONS}

$\mathrm{CC}, \mathrm{GW}, \mathrm{BK}, \mathrm{MD} \& \mathrm{DH}$ all contributed to the proposal development.

CC collected and analysed the data, contributed to the manuscript.

GW provided academic support to $\mathrm{CC}$, contributed to data analysis and wrote the manuscript. 
BK provided academic support to $\mathrm{CC}$ and contributed to manuscript preparation.

DH contributed to manuscript preparation.

\section{AUTHORS' INFORMATION}

$\mathrm{CC}$ is Respiratory Specialist Nurse Matron.

GW is a Lecturer in Adult Nursing.

BK is a Research Midwife.

MD is Medical Director and Consultant Physician.

DH is Consultant Respiratory Physician \& Honorary Associate Professor.

\section{CONFLICT OF INTEREST}

The authors confirm that this article content has no conflict of interest.

\section{ACKNOWLEDGEMENTS}

This study was funded by internal research funds from the Royal Devon and Exeter Foundation NHS Trust small grants programme. Help in proposal development was obtained from the trust's Research Design Service.

\section{REFERENCES}

[1] NAEPP expert panel report. Managing asthma during pregnancy: recommendations for pharmacologic treatment-2004 update. J Allergy Clin Immunol 2005; 115(1): 34-46.

[2] British Thoracic Society. British Guideline on the Management of Asthma. A national clinical guideline 2012. British Thoracic Society/Scottish Intercollegiate Guidelines Network. Available at: http://www.britthoracic.org.uk/Portals/0/Guidelines/AsthmaGuideli nes/sign 101\%20Jan\%202012.pdf

[3] Martel MJ, Rey E, Beauchesne MF, et al. Control and severity of asthma during pregnancy are associated with asthma incidence in offspring: two-stage case-control study. Eur Resp J 2009; 34(3): 579-87.

[4] Laprise C, Blanchette MA. Controlling asthma during pregnancy prevents asthma in children: a Berkson fallacy? Eur Resp J 2010; 35(6): 1423-4

[5] Carmichael SL, Shaw GM, Ma C, Werler MM, Rasmussen SA, Lammer EJ. Maternal corticosteroid use and orofacial clefts. Am J Obstet Gynecol 2007; 197(6): 585-7.

[6] Vatti RR, Teuber SS. .Asthma and Pregnancy. Clin Rev Allergy Immunol 2012; 43(1-2): 45-56.

[7] Rocklin RE. Asthma, asthma medications and their effects on maternal/fetal outcomes during pregnancy. Reprod Toxicol 2011; 32(2): 189-97.

[8] Lim AS, Stewart K, Abramson MJ, Ryan K, George J. Asthma during pregnancy: the experiences, concerns and views of pregnant women with asthma. J Asthma 2012; 49(5): 474-9.

[9] Enriquez R, Wu P, Griffin MR, et al. Cessation of asthma medication in early pregnancy. Am J Obstet Gynecol 2006; 195(1): $149-53$.
[10] Powell H, McCaffery K, Murphy VE, et al. Psychosocial outcomes are related to asthma control and quality of life in pregnant women with asthma. J Asthma 2011, 48(10): 1032-40.

[11] Lim AS, Stewart K, Abramson MJ, George J. 1 Management of asthma in pregnant women by general practitioners: a cross sectional survey. BMC Fam Pract 2011; 12: 121.

[12] Cimbollek S, Plaza V, Quirce S, et al. Knowledge, attitude and adherence of Spanish healthcare professionals to asthma management recommendations during pregnancy. Allergol Immunopathol 2012; 41(2): 114-20.

[13] Murphy VE, Gibson PG, Talbot PI, et al. Asthma self management skills and the use of asthma education during pregnancy. Eur Resp J 2005; 26(3): 435-41.

[14] Beckmann CA. A descriptive study of women's perceptions of their asthma during pregnancy. MCN Am J Matern Child Nurs 2002; 27(2): 98-102.

[15] Caelli K, Ray L, Mill J. 'Clear as mud': Toward greater clarity in generic qualitative research. Int J Q Methods 2003; 2(2). Article 1. Available at: http://www.ualberta.ca/ iiqm/backissues/pdf/caellieta l.pdf

[16] Whittaker A, Williamson GR. Succeeding in Research Project Plans and Literature Reviews. Exeter: Learning Matters 2011.

[17] Cooper S, Endacott R. Generic qualitative research: a design for qualitative research in emergency care? Emerg Med J 2007: 24(12): 816-9.

[18] Ritchie J, Spencer L, O'Connor, W. Carrying out qualitative data analysis In: Richie J, Lewis J, Eds. Qualitative Research Practice London: SAGE 2003: pp. 219-62.

[19] Cutcliffe M, McKenna H. Establishing the credibility of qualitative research findings: the plot thickens. J Adv Nurs 1999; 30: 374-80.

[20] Powell H, McCaffery K, Murphy V E, Hensley MJ, Clifton VL, Giles, W. Gibson PG. Psychosocial Variables Are Related to Future Exacerbation Risk and Perinatal Outcomes in Pregnant Women with Asthma. Asthma 2013. [doi: 10.3109/02770903.20 12.757777].

[21] McCallister JW. Asthma in pregnancy: management strategies. Curr Opin Pulm Med 2013; 19(1): 13-17.

[22] Tegethoff M, Olsen J, Schaffner E, Meinlschmidt G. Asthma during pregnancy and clinical outcomes in offspring: a national cohort study. Pediatrics 2013; 132: 483.

[23] Lim A, Stewart K, Abramson MJ, Walker SP, Johnson G. Multidisciplinary approach to management of maternal asthma (MAMMA [copyright]): the PROTOCOL for a randomized controlled trial. BMC Public Health 2012; 12: 1094.

[24] McLaughlin K, Keatinge D, Murphy V, Ebert L, Kable A Midwives current knowledge of asthma in pregnancy and their perceived role in antenatal asthma management - a qualitative descriptive study (2013). HNE Handover: For Nurses and Midwives vol. 6, no. 1 (2013) Special Issue. Australian Nursing and Midwifery Conference. $17^{\text {th }} \& 18^{\text {th }}$ October 2013. Available at: http://journals.sfu.ca/hneh/index.php/hneh/article/vie w/236/134

[25] Neergaard MA, Olesen F, Andersen RA, Sondergaard J. Qualitative description - the poor cousin of health research? BMC Med Res Methodol 2009; 9: 52.

[26] Gale N K, Heath G Cameron E, Rashid S, Redwood S. Using the framework method for the analysis of qualitative data in multidisciplinary health research. BMC Med Res Methodol 2013; 13: 117.

[27] Lim, A.Optimising the management of asthma during pregnancy. Unpublished Doctoral Thesis. 2014. Monash University, Australia. Available at: http://arrow.monash.edu.au/vital/access/manager/Rep ository/monash:120591 